\title{
INTEGRATING DIFFERENT STABILITY MODELS TO INVESTIGATE HIGH YIELDING SAFFLOWER (Carthamus tinctorius L.) GENOTYPES
}

\author{
Hasan $\mathrm{KOC}^{1^{*}}$ \\ ${ }^{1}$ Bahri Dagdas International Agricultural Research Institute, Konya, TURKEY \\ *Corresponding author: koc175@hotmail.com
}

Received: 19.09.2020

\begin{abstract}
This study was conducted to investigate seed yield stability of the safflower (Carthamus tinctorius L.) genotypes grown for five years (2014-2018) under different climate conditions of Central Anatolia Region with large differences in climate conditions year to year in Turkey. A total of 17 safflower genotypes were used in this study. Experiments were conducted in randomized blocks design with four replications. The parameters of $\mathbf{S}^{(1)}$, $\mathbf{S}^{(2)}, \mathbf{S}^{(3)}, \mathbf{S}^{(6)}, \mathbf{N P}^{(1)}, \mathbf{N P}^{(2)}, \mathbf{N P}^{(3)}, \mathbf{N P}^{(4)}, \mathbf{W}_{\mathrm{i}}^{2}, \sigma_{\mathrm{i}}^{2}, \mathbf{s}^{2} \mathrm{~d}_{\mathrm{i}}, \mathrm{b}_{\mathrm{i}}, \mathrm{CVi}, \boldsymbol{\theta}_{(\mathrm{i})}$ and $\boldsymbol{\theta}_{\mathrm{i}}, K \mathrm{R}$ were used to determine seed yield stability of the genotypes. Biplot graphs were used for visual assessment of the relationships among the methods utilized. Gokturk, Dincer 5-118, G5 and G9 genotypes were identified as stable based on majority of the methods and they had seed yields greater than the general averages $\left(2.90,2.85,2.83\right.$ and $2.82 \mathrm{t} \mathrm{ha}^{-1}$, respectively). Based on the relationships among the methods, present parameters were divided into four groups. Present findings

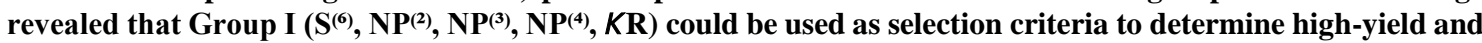
stable genotypes. Instead of using several methods to identify stable genotypes, a single parameter from each group of methods will be sufficient. The stable and high-yield genotype G9 was registered in 2019 in Turkey under the name of "Koc".
\end{abstract}

Key words: Safflower, seed yield, stability, parametric, non-parametric

\section{INTRODUCTION}

Plant breeders generally focus on optimum use of available resources for development and selection of new varieties. Together with climate change, potential use of available varieties is not able to be foreseen. Global warming and excessive changes in climate conditions of sure influence agricultural production activities, but it is hard to estimate yield losses or to decide about new breeding strategies for resistance to new stressors (Semenov and Halford, 2009). Therefore, the genotypes able to sustain a certain yield level have become prominent.

If the same genotype exhibits significant differences when grown in different environments, it is then worth to mention about "genotype $\times$ environment interaction". Genotype $\times$ environment interaction (GEI) is quite a significant issue for plant breeders in cultivar development programs. Since several genes with additive effect play a role in heredity of quantitative traits, there mostly exists genotype $\times$ environment interaction in such traits. Therefore, it is quite significant to identify highly stable genotypes with the best adaptation to a certain environment (Simmonds, 1991).

Parametric and non-parametric analyses are used to interpret GEI in single-variable stability analyses (Sozen et al., 2018). The first group of parametric statistics is commonly used for assessment of yield-like quantitative traits with an economical value (Akcura et al., 2006; Sozen et al., 2018). For parametric statistics to be efficient, data should be normally distributed, variance should be homogeneous and GEI should be significant in combined variance analysis (Akcura and Turan, 2020).

Commonly used parametric statistics include; $\left(b_{i}\right)$ regression coefficient (Finlay and Wilkinson, 1963), $\left(\mathrm{S}^{2} \mathrm{~d}_{\mathrm{i}}\right)$ variance of deviation from the regression (Eberhart and Russell, 1966), $\left(\mathrm{W}_{\mathrm{i}}^{2}\right)$ Wricke's equivalence stability index (Wricke, 1962), $\left(\sigma_{\mathrm{i}}^{2}\right)$ Shukla's stability variance (Shukla, 1972), $\left(\mathrm{CV}_{\mathrm{i}}\right)$ environmental variation coefficient (Francis and Kannenberg, 1978), $\left(\theta_{\mathrm{i}}\right)$ mean variance (Plaisted and Peterson, 1959), $\left(\theta_{(\mathrm{i})}\right)$ GE variance component (Plaisted $1960)$ and $\left(\mathrm{YS}_{\mathrm{i}}\right)$ yield stability index (Kang, 1993).

The second group is non-parametric methods (Akcura and Kaya, 2008). As it was in parametric methods, GEI should be significant, variance should be homogeneous and data should be normally distributed also in non-parametric analysis methods (Huehn, 1990).

When the parametric methods are employed for stability, estimations are made data interval and homogeneity of the variance. On the other hand, non- 
parametric methods depend on the rankings rather than the values, thus a genotype with a relatively better ranking is accepted as stable (Flores et al., 1998).

Non-parametric stability analyses include Nassar and Huehn's statistics (S ${ }^{(1)}, S^{(2)}$; Nassar and Huehn, 1987), Huehn's statistics $\left(\mathrm{S}^{(3)}\right.$ and $\mathrm{S}^{(6)}$; Huehn, 1990), Thennarasu's statistics (NP(i); Thennarasu, 1995), Kang's ranking total (KR; Kang, 1993) and Fox's top rank (top rank; Fox et al., 1990). Non-parametric statistics calculated from ranking data are considered as the alternative of parametric statistics (Nassar and Huehn, 1987). Therefore, they are conveniently utilized in different studies, especially in resistance breeding studies (Hocaoglu et al., 2020).

When the genotype - environment interactions are significant, couple parametric and non-parametric stability methods are used to put forth stability performance of the genotypes. Since available stability parameters yield different outcomes, such differences may sometimes result in erroneous decisions about the stability of the genotypes. A single method maybe sufficient to assess the stability performance of the genotypes among the environments. Various stability parameters are compared and statistical relationships among them are determined to make these methods more useful (Y1ldırım et al., 1992).

Stability analyses not only used to assess the data obtained from different locations, but also to compare the genotypes grown in the same environments for multiple years (Akcura et al., 2006).

Safflower is an oil crop cultivated in Turkey under dry climate conditions without irrigation (Koc, 2020). Climate differences in safflower cultivated regions and irregular precipitation in the same region result in significant decreases in safflower seed yields. Therefore, it is quite significant to develop cultivars able to adapt to different climate conditions. Researchers mostly focus on genotype stability in different regions or different climate conditions of the same region in different years.

This study was conducted to investigate seed yield stability of the safflower genotypes grown for five years under different climate conditions of Central Anatolia Region with the greatest differences in climate conditions in Turkey. Parametric and non-parametric stability methods were employed for this purpose. Secondary objective of the present study was set as to investigate the parameters to be used for yield and the relationships among the stability parameters.

\section{MATERIALS AND METHODS}

\section{Field Trials}

Experiments were conducted with 4 registered cultivars (Gokturk, Dincer 5-118, Balc1, Linas) and 13 genotypes developed through breeding studies (Table 1) over the experimental fields of Bahri Dagdas International Agricultural Research Institute in Central Anatolia Region of Turkey for 5 years (2014-2018). Experimental design was randomized blocks with four replications. Experimental plots were $5 \mathrm{~m}$ long and $1.2 \mathrm{~m}$ wide $\left(6 \mathrm{~m}^{2}\right)$. Sowing was performed at the end of March as to have 125 seeds per square meter with a plot sowing machine. Harvest was performed in the second week of August with a plot harvester.

Table 1. Pedigree and selection history of genotypes used in the research

\begin{tabular}{cllcl}
\hline No & Genotype & Pedigree & Oil Content (\%) & Appearance \\
\hline 1 & G1 & PI 560172/PI 525458 & 35.86 & Spiny, yellow florets \\
2 & G2 & Gokturk/PI 306686 & 36.22 & Spiny, yellow-orange florets \\
3 & G3 & PI 560172/PI 537606 & 36.88 & Spiny, yellow-orange florets \\
4 & G4 & PI 537606/Linas & 35.37 & Spiny, yellow-orange florets \\
5 & G5 & PI 537665/ Dincer 5-118 & 36.38 & Spineless, red florets \\
6 & G6 & PI 537607/Gokturk & 36.79 & Spiny, yellow-orange florets \\
7 & G7 & PI 560172/PI 537703 & 39.08 & Spiny, yellow-orange florets \\
8 & G8 & PI 537110/PI 544018 & 39.45 & Spiny, yellow florets \\
9 & G9 & PI 306686/PI537665 & 39.06 & Spiny, yellow florets \\
10 & G10 & PI 401584/PI 537110 & 37.00 & Spiny, yellow-orange florets \\
11 & G11 & PI 401589/PI 537110 & 34.99 & Spiny, red florets \\
12 & G12 & PI 401589/PI 537607 & 35.50 & Spiny, yellow-orange florets \\
13 & G13 & Balc1/PI 401584 & 35.30 & Spiny, yellow florets \\
14 & Gokturk & Registered in Turkey & 34.60 & Spiny, yellow-orange florets \\
15 & Dincer 5-118 & Registered in Turkey & 29.80 & Spineless, red florets \\
16 & Linas & Registered in Turkey & 36.00 & Spiny, yellow-orange florets \\
17 & Balc1 & Registered in Turkey & 35.12 & Spiny, yellow florets \\
\hline
\end{tabular}

Annual precipitations of the experimental years (20142018), precipitation and temperature values during the vegetation period are provided in Table 2. Experimental soils were sandy-loam in texture with moderate organic matter level (2.3\%). Soils were slightly alkaline (pH: 7.8). Soil lime content was high $(29 \%)$. Soil was rich in phosphorus and potassium. Salinity was not encountered in experimental soils. 
Table 2. Agro-climatic characteristics of environments in yield stability experiments for 17 safflower genotypes

\begin{tabular}{cccccc}
\hline & & & \multicolumn{3}{c}{ Means Temperature $\left({ }^{\circ} \mathbf{C}\right)$} \\
\cline { 4 - 6 } Years & TP $(\mathbf{m m})$ & VPP $(\mathbf{m m})$ & Min. & Max & Ort. \\
\hline 2014 & 366 & 100 & 5.6 & 19.1 & 11.9 \\
2015 & 309 & 165 & -4.3 & 25.3 & 11.2 \\
2016 & 201 & 101 & 1.1 & 26.9 & 12.3 \\
2017 & 320 & 178 & -0.7 & 24.7 & 11.7 \\
2018 & 361 & 181 & 1.1 & 27.4 & 12.6 \\
YM & 322 & 106 & -3.9 & 26.1 & 11.0 \\
\hline
\end{tabular}

TP: Total precipitation, VPP: Vegetation period precipitation, YM: Years Means (1960-2018)

\section{Statistical Analyses}

The parameters used in this study and calculation methods are provided below:

\section{Parametric Statistics}

$b_{i}$ (Regression coefficient): It is the respond of the genotype to environmental index derived from the average performance of the entire genotypes in every environment. If the regression coefficient is close to 1 , then the genotype stability is considered as high (Finlay and Wilkinson 1963; Eberhart and Russell 1966). Regression of genotype values of each genotype in different environments is taken over the environment averages $b_{i}$ ).

$$
b_{i}=\sum_{j} X_{i j}(\bar{X} \cdot j-\bar{X}) / \sum_{j}(\bar{X} \cdot j-\bar{X})^{2}
$$

$\mathrm{S}^{2} \mathrm{~d}_{\mathrm{i}}$ (variance of deviation from the regression): Besides regression coefficient, variance of deviation from the regression is recommended as one of the parameters mostly used for selection of stable genotypes (Eberhart and Rusell 1966).

$$
S^{2} d_{i=} \sum_{j=1}^{q}\left(X_{i j}-\bar{X}_{i .}\right)^{2} /(q-1)
$$

$\mathrm{W}_{\mathrm{i}}{ }^{2}$ (stability index): Wrick (1962) recommended the term of equivalence as the contribution of the genotype to sum of squares of GEI. Accordingly, the genotypes with a low $W i^{2}$ value are more stable. The genotypes with a low equivalence value are excepted stable.

$$
\mathrm{W}_{\mathrm{i}}^{2}=\sum_{j=1}^{q}\left(X_{i j}-\bar{X}_{i \cdot}-\bar{X}_{\cdot j+}+\bar{X}_{. .}\right)^{2}
$$

$\sigma_{\mathrm{i}}^{2}$ (stability variance): Shukla (1972) recommended stability variance of the genotype following the removal of main effects of environmental tools as the variance among the environments. Accordingly, genotypes with minimum values are considered as more stable.

$$
\sigma_{i}^{2}=\frac{p}{(p-2)(q-1)} \sum_{j=1}^{q}\left(X i j-\bar{X} i .-\bar{X} . j+\bar{X}_{. .}\right)^{2}-\frac{S S(G X E)}{(p-1)(p-2)(q-1)}
$$

$\mathrm{CV}_{\mathrm{i}}$ (environmental variation coefficient): Francis and Kannenberg (1978) recommended this coefficient of variation obtained through the combination of mean yield and environmental variation as a stability statistic. Genotypes are desired to have low $\mathrm{CV}_{\mathrm{i}}$, low environmental variance and high mean yield.

\section{$C V i=S Y i / Y i) \times 100$}

$\theta_{\mathrm{i}}$ (Mean variance): Mean of estimation for all combinations with a common genotype is considered as a measure of stability. Accordingly, the genotypes with a greater $\theta_{\mathrm{i}}$ value are considered as more stable (Plaisted and Peterson, 1959).

$$
\frac{\theta_{\mathrm{i}}=}{2(p-1)(q-1)} \sum_{j=1}^{q}\left(X_{i j}-\bar{X}_{i}-\bar{X}_{. j}+\bar{X}_{. .}\right)^{2}+\frac{S S(G X E)}{2(p-1)(q-1)}
$$

$\theta_{\text {(i) }}$ (GE variance component): According to this statistic, the genotypes with greater values are considered as more stable (Plaisted, 1960).

$$
\frac{-p}{\theta_{(\mathrm{i})}=} \frac{-p}{(p-1)(p-2)(q-1)} \sum_{j=1}^{q}\left(X_{i j}-\bar{X}_{i .}-\bar{X} . j+\bar{X}_{. .}\right)^{2}+\frac{S S(G X E)}{(p-2)(q-1)}
$$

$\mathrm{YS}_{\mathrm{i}}$ (Kang's yield stability index): A rank is assigned to the genotype with the greatest mean yield and genotypes are ranked based on yield performance (Kang, 1993).

For all parameters, $\bar{X}_{i}$ is the mean grain yield of genotype $\mathrm{I} ; \overline{\mathrm{X}}_{\mathrm{J}}$ is the mean grain yield of the environment $\mathrm{j}$; $\overline{\mathrm{X}} i_{\mathrm{J}}$ : the seed yield of genotype $\mathrm{i}$ in environment $\mathrm{j} ; \bar{X}$ is the mean seed yields of genotypes; $P$ is number of genotypes; q: the number of environments; SS is Sum of Square; GXE is genotype and environment interaction; $\mathrm{SYi}$ is standard deviation of a genotype; Yi is mean seed yields.

\section{Non-parametric Statistics}

$\mathrm{S}^{(1)}$ : Mean of absolute rankings of a genotype based on the environments of that time (Nassar and Huehn, 1987).

$$
S^{(1)}=2 \sum_{j}^{n-1} \sum_{j^{\prime}=j+1}^{n}\left|r_{i j}-r_{i j^{\prime}}\right| /[n(n-1)]
$$

$S$ (2): The difference in rankings of environments (Nassar and Huehn 1987).

$$
S^{(2)}=\sum_{j=1}^{n}\left(r_{i j}-\overline{r_{i}}\right)^{2} /(n-1)
$$

$\mathrm{S}^{(3)}$ : Absolute deviations of each genotype from the mean of rankings (Nassar and Huehn 1987). 


$$
S^{(3)}=\sum_{j=1}^{n}\left(r_{i j}-\bar{r}_{i}\right)^{2} / \bar{r}_{i}
$$

$S^{(6)}$ : Sum of squares of rankings (Nassar and Huehn, 1987).

$$
S^{(6)}=\sum_{j=1}^{n}\left|r_{i j}-\bar{r}_{i}\right| / \bar{r}_{i}
$$

where rij, $\overline{\mathrm{r}}_{\mathrm{iJ}}$ rij and $\mathrm{n}$ are the rank of the $\mathrm{i}$ th genotype in the jth environment, mean rank across all environments for each genotype, and number of environments, respectively (Vaezi et al., 2019).

KR: Sum of rankings: For each genotype, yield and stability variance rankings are summed. The genotypes with the lowest sum of rankings are desired (Kang, 1993).

RM-Rank mean (Ketata, 1988).

$$
R M=r_{i j} / n
$$

$\mathrm{NP}^{(1-4)}$ : These parameters are calculated from the positions of the genotypes in each environment with respect to the others (Thennarasu, 1995).

$$
\begin{gathered}
N P_{i}^{1}=\sum_{j=1}^{n}\left|r_{i j}^{*}-M_{d i}^{*}\right| / n \\
N P_{i}^{2}=\left[\sum_{j=1}^{n}\left|r_{i j}^{*}-M_{d i}^{*}\right| / M_{d i}\right] / n \\
N P_{i}^{3}=\sqrt{\left(r_{i j}^{*}-\overline{\left.r_{i}^{*}\right)^{2} / n} / \overline{r_{i}}\right.}
\end{gathered}
$$

$$
N P_{i}^{4}=\frac{2}{n(n-1)}\left[\sum_{j=1}^{n-1} \sum_{\left[j^{\prime}=j+1\right]}^{n}\left|r_{i j}^{*}-r_{i j^{\prime}}^{*}\right| / \overline{r_{i}}\right]
$$

Where $r_{i j}^{*}, \overline{r_{i}^{*}} M_{d i}^{*}, r_{i j}^{*}$ and Mdi are the rank of the $\mathrm{i}$ th genotype in the $\mathrm{j}$ th environment based on adjusted data, mean rank for adjusted data, median rank for adjusted data, the last same parameters obtained from the original data (unadjusted), respectively. (Vaezi et al., 2019).

Combined variance analysis over 5-year data on seed yield and Spearman ranking correlation were conducted with the use of JMP software. Stability analysis of means obtained for locations with the use of Stabilitysoft software (Pour-Aboughadareh et al., 2019). In Stabilitysoft software, 16 parametric and non-parametric stability parameters were used. Biplot analysis was used to assess the grouping of stability parameters (Yan, 2014).

\section{RESULTS AND DISCUSSION}

According to variance analysis on 5-year seed yield data (Table 3), genotypes, years and genotype $\times$ year interactions were found to be significant at $1 \%$ level.

Mean seed yield $(\mathrm{Y})$ values and 16 parametric and nonparametric stability values of safflower genotypes for 5 years are provided in Table 4. Ranking analysis of these values is provided in Table 5 .

Table 3. Combined analysis of variance for seed yield of 17 safflower genotypes grown at 5 years

\begin{tabular}{lcccc}
\hline SV & DF & SS & MS & F \\
\hline Year (Y) & 4 & 84.5 & 21.1 & $34.1 * *$ \\
Rep. [Year] & 15 & 9.2 & 0.6 & $5.7 * *$ \\
Genotyp (G) & 16 & 18.2 & 1.1 & $2.9 * *$ \\
G x Y & 64 & 37.7 & 0.5 & 0.2 \\
Error & 240 & 47.7 & & \\
\hline
\end{tabular}

SV: Source of Variance, DF: Degrees of Freedom, SS: Sums of Squares, MS: Mean Square, ${ }^{* *} \mathrm{P}<0.01$ significant.

Mean seed yields of the genotypes varied between 2.23 - $2.99 \mathrm{t} \mathrm{ha}^{-1}$ (G1-G12) (Table 4). The lowest values for total rankings and mean rankings of all parameters were obtained from Gokturk, G5, G9, G8, Dincer 5-118, G2, G4, G1 and G12 genotypes and these genotypes were defined as the most stable ones (Table 5). Gokturk, Dincer 5-118, G5 and G9 genotypes had seed yields greater than the average respectively as $2.90,2.85,2.83$ and $2.82 \mathrm{t} \mathrm{ha}^{-1}$. Of these genotypes, Gokturk and Dincer 5-118 are registered cultivars and used as standard cultivars in this study. Of advanced lines, G5 and G9 are high-yield and stable genotypes. Although G12 had the greatest yield, it had middle positions in general stability average and total. On the other hand, genotypes G8, G4 and G1 with yield levels lower than the average had well stability averages (Table 4 and Table 5).

The genotypes with a value of deviation from the regression $\left(\mathrm{S}^{2} \mathrm{di}\right)$ close to zero are accepted as stable (Eberhart and Russell, 1966). The genotypes with a low $\mathrm{W}_{\mathrm{i}}{ }^{2}$ (stability index) value (Wrick, 1962) and a low $\sigma_{i}^{2}$ (stability variance) value are also accepted as stable (Shukla, 1972). According to parametric stability parameters of $\mathrm{s}^{2} \mathrm{~d}_{\mathrm{i}}, \mathrm{W}_{\mathrm{i}}{ }^{2}$ and $\sigma^{2}$, Gokturk and G5 genotypes with a seed yield value of greater than the average was identified as stable genotypes (Table 4 and Table 5). 
Table 4. Mean seed yield (t ha-1) and 16 stability parameters of 17 safflower genotypes across 5 years

\begin{tabular}{|c|c|c|c|c|c|c|c|c|c|c|c|c|c|c|c|c|c|}
\hline Gen. & $\mathbf{Y}$ & $\mathbf{S}^{(\mathbf{1})}$ & $\mathbf{S}^{(\mathbf{2})}$ & $\mathbf{S}^{(\mathbf{3})}$ & $\mathbf{S}^{(\boldsymbol{6})}$ & NP1 & $\mathbf{N}^{2}$ & $\mathbf{N P}^{3}$ & $\mathrm{NP}^{4}$ & $\mathbf{W}_{\mathrm{i}}^{2}$ & $\sigma_{i}^{2}$ & $\mathbf{s}^{2} \mathbf{d}_{\mathrm{i}}$ & $b_{i}$ & $\mathrm{CV} i$ & $\boldsymbol{\theta}_{(\mathrm{i})}$ & $\theta_{\mathrm{i}}$ & $K \mathbf{R}$ \\
\hline G12 & 2.99 & 4.6 & 14.7 & 4.5 & 1.1 & 5.0 & 0.18 & 0.39 & 0.35 & 509 & 135 & 29 & 1.49 & 28 & 139 & 142 & 13 \\
\hline Gokturk & 2.90 & 1.8 & 2.3 & 0.7 & 0.4 & 3.4 & 0.18 & 0.31 & 0.14 & 151 & 33 & 17 & 1.14 & 22 & 146 & 94.5 & 6 \\
\hline $\begin{array}{l}\text { Dincer } \\
5-118\end{array}$ & 2.87 & 4.0 & 11.3 & 3.8 & 1.0 & 3.4 & 0.30 & 0.42 & 0.34 & 436 & 114 & 56 & 0.82 & 19 & 141 & 132 & 13 \\
\hline G10 & 2.86 & 5.4 & 18.3 & 6.3 & 1.41 & 4.4 & 0.27 & 0.43 & 0.46 & 976 & 267 & 135 & 0.85 & 23 & 131 & 204 & 19 \\
\hline G5 & 2.85 & 3.4 & 7.5 & 2.5 & 0.8 & 3.6 & 0.14 & 0.37 & 0.28 & 140 & 30 & 10 & 1.23 & 24 & 146 & 93.1 & 8 \\
\hline G6 & 2.84 & 5.0 & 17.5 & 5.8 & 1.5 & 6.0 & 0.22 & 0.54 & 0.41 & 360 & 92 & 45 & 1.18 & 25 & 142. & 122 & 15 \\
\hline G13 & 2.83 & 6.6 & 34.5 & 12.5 & 1.8 & 4.2 & 0.27 & 0.47 & 0.60 & 939 & 256 & 134 & 0.98 & 25 & 132 & 199 & 14 \\
\hline G9 & 2.82 & 3.2 & 6.8 & 2.1 & 0.8 & 4.2 & 0.13 & 0.37 & 0.25 & 234 & 56 & 32 & 0.92 & 20 & 144 & 105 & 14 \\
\hline G2 & 2.79 & 3.4 & 11.5 & 4.1 & 1.0 & 2.8 & 0.2 & 0.35 & 0.30 & 343 & 88 & 47 & 0.89 & 20 & 142 & 120 & 17 \\
\hline G7 & 2.49 & 7.4 & 43.0 & 28.6 & 3.6 & 5.2 & 0.93 & 0.96 & 1.23 & 1502 & 41 & 100 & 1.79 & 43 & 122 & 273 & 28 \\
\hline Balcı & 2.47 & 5.6 & 22.0 & 12.5 & 2.8 & 6.4 & 0.72 & 0.77 & 0.80 & 499 & 132 & 12 & 0.42 & 11 & 140 & 140 & 22 \\
\hline G11 & 2.46 & 6.6 & 37.3 & 27.6 & 3.9 & 4.2 & 1.16 & 0.98 & 1.22 & 1572 & 436 & 224 & 0.95 & 33 & 121 & 283 & 29 \\
\hline G8 & 2.45 & 3.2 & 6.8 & 4.2 & 1.5 & 2.4 & 0.80 & 0.42 & 0.50 & 88.5 & 15 & 6 & 0.82 & 19 & 147 & 86.1 & 15 \\
\hline Linas & 2.42 & 6.4 & 35.2 & 20.7 & 3.0 & 4.4 & 0.85 & 0.69 & 0.94 & 630 & 169 & 55 & 0.56 & 18 & 137 & 158 & 27 \\
\hline G3 & 2.37 & 3.0 & 7.3 & 5.2 & 1.6 & 3.8 & 1.20 & 0.88 & 0.53 & 220 & 53 & 27 & 1.15 & 28 & 144 & 103 & 20 \\
\hline G4 & 2.28 & 2.4 & 4.2 & 4.4 & 1.8 & 0.8 & 1.80 & 0.30 & 0.63 & 60.2 & 7 & 7 & 1.07 & 26 & 147 & 82.4 & 17 \\
\hline G1 & 2.23 & 1.8 & 2.3 & 2.5 & 1.7 & 5.0 & 2.28 & 1.31 & 0.50 & 266 & 66 & 18 & 0.66 & 18 & 144 & 109 & 24 \\
\hline
\end{tabular}

Y: seed yield means of genotypes $\left(\mathrm{t} \mathrm{ha}^{-1}\right), \mathrm{S}^{(1)}, \mathrm{S}^{(2)}, \mathrm{S}^{(3)}$ and $\mathrm{S}^{(6)}$ : Nassar and Huehn's non-parametric statistics and Huehns statistic, $\mathrm{NP}^{(1-4)}$ Ranks of adjusted seed yield means of genotypes (Thennarasu, 1995), $\mathrm{W}_{\mathrm{i}}^{2}$ : Wricke's ecovalence stability index (Wricke,1962), $\sigma_{\mathrm{i}}^{2}$ : Shukla's stability variance (Shukla, 1972), $\mathrm{S}^{2} \mathrm{~d}_{\mathrm{i}}$ : Deviation from regression (Eberhart and Russell, 1966), $\mathrm{b}_{\mathrm{i}}$ : regression coeffient (Finlay and Wilkinson,1963), $\mathrm{CV}_{\mathrm{i}}$ : Environmental coefficient of variance (Francis and Kannenberg, 1978), $\theta_{(\mathrm{i})}$ : GE variance component (Plaisted, 1960), $\theta_{\mathrm{i}}$ : Mean variance component (Plaisted ve Peterson, 1959), KR: Kang's rank-sum (Kang,1993).

Table 5. Ranks of 17 genotypes on mean yield and stability methods

\begin{tabular}{|c|c|c|c|c|c|c|c|c|c|c|c|c|c|c|c|c|c|c|c|}
\hline Gen. & $\mathbf{Y}$ & $\mathbf{S}^{(\mathbf{1})}$ & $\mathbf{S}^{(2)}$ & $\mathbf{S}^{(\mathbf{3})}$ & $\mathbf{S}^{(\boldsymbol{6})}$ & $\mathbf{N P}^{(\mathbf{1})}$ & $\mathbf{N P}^{(2)}$ & $\mathbf{N P}^{(\mathbf{3})}$ & $\mathbf{N P}^{(4)}$ & $\mathbf{W}_{\mathrm{i}}{ }^{2}$ & $\sigma^{2}{ }_{i}$ & $\mathbf{s}^{2} d_{i}$ & $\mathbf{b}_{\mathbf{i}}$ & $\mathrm{CVi}$ & $K \mathrm{R}$ & $\boldsymbol{\theta}_{\text {(i) }}$ & $\theta_{\mathrm{i}}$ & KR & $\mathbf{R M}$ \\
\hline G12 & 1 & 10 & 10 & 9 & 6 & 13 & 4 & 6 & 6 & 12 & 12 & 8 & 16 & 15 & 3 & 12 & 6 & 149 & 8.7 \\
\hline Gokturk & 2 & 1 & 1 & 1 & 1 & 4 & 3 & 2 & 1 & 4 & 4 & 5 & 12 & 8 & 1 & 4 & 14 & 68 & 4.0 \\
\hline $\begin{array}{l}\text { Dincer } \\
5-118\end{array}$ & 3 & 9 & 8 & 5 & 4 & 4 & 9 & 7 & 5 & 10 & 10 & 13 & 5 & 5 & 3 & 10 & 8 & 118 & 6.9 \\
\hline G10 & 4 & 12 & 12 & 12 & 7 & 11 & 8 & 9 & 8 & 15 & 15 & 16 & 6 & 9 & 11 & 15 & 3 & 173 & 10.1 \\
\hline G5 & 5 & 7 & 7 & 3 & 3 & 6 & 2 & 4 & 3 & 3 & 3 & 3 & 15 & 10 & 2 & 3 & 15 & 94 & 5.5 \\
\hline G6 & 6 & 11 & 11 & 11 & 9 & 16 & 6 & 11 & 7 & 9 & 9 & 10 & 14 & 11 & 7 & 9 & 9 & 166 & 9.7 \\
\hline G13 & 7 & 15 & 14 & 13 & 12 & 8 & 7 & 10 & 12 & 14 & 14 & 15 & 10 & 12 & 5 & 14 & 4 & 185 & 10.8 \\
\hline G9 & 8 & 5 & 4 & 2 & 2 & 8 & 1 & 5 & 2 & 6 & 6 & 9 & 8 & 6 & 5 & 6 & 12 & 95 & 5.6 \\
\hline G2 & 9 & 7 & 9 & 6 & 5 & 3 & 5 & 3 & 4 & 8 & 8 & 11 & 7 & 7 & 9 & 8 & 10 & 119 & 7.0 \\
\hline G7 & 10 & 17 & 17 & 17 & 16 & 15 & 13 & 15 & 17 & 16 & 16 & 14 & 17 & 17 & 15 & 16 & 2 & 250 & 14.7 \\
\hline Balc1 & 11 & 13 & 13 & 14 & 14 & 17 & 10 & 13 & 14 & 11 & 11 & 4 & 1 & 1 & 13 & 11 & 7 & 178 & 10.4 \\
\hline G11 & 12 & 15 & 16 & 16 & 17 & 8 & 14 & 16 & 16 & 17 & 17 & 17 & 9 & 16 & 17 & 17 & 1 & 241 & 14.2 \\
\hline G8 & 13 & 5 & 4 & 7 & 8 & 2 & 11 & 8 & 9 & 2 & 2 & 1 & 4 & 4 & 7 & 2 & 16 & 105 & 6.2 \\
\hline Linas & 14 & 14 & 15 & 15 & 15 & 11 & 12 & 12 & 15 & 13 & 13 & 12 & 2 & 2 & 16 & 13 & 5 & 199 & 11.7 \\
\hline G3 & 15 & 4 & 6 & 10 & 10 & 7 & 15 & 14 & 11 & 5 & 5 & 7 & 13 & 14 & 12 & 5 & 13 & 166 & 9.7 \\
\hline G4 & 16 & 3 & 3 & 8 & 13 & 1 & 16 & 1 & 13 & 1 & 1 & 2 & 11 & 13 & 9 & 1 & 17 & 129 & 7.6 \\
\hline G1 & 17 & 1 & 2 & 4 & 11 & 13 & 17 & 17 & 9 & 7 & 7 & 6 & 3 & 3 & 14 & 7 & 11 & 149 & 8.7 \\
\hline
\end{tabular}

Y: Yield mean ranks, $S^{(1)}, S^{(2)}, S^{(3)}$ and $S^{(6)}$ : Nassar and Huehn's non-parametric statistics and Huehns statistic, NP(1-4) $:$ Ranks of adjusted seed yield means of genotypes (Thennarasu, 1995), $\mathrm{W}_{\mathrm{i}}^{2}$ : Wricke's ecovalence stability index (Wricke,1962), $\sigma_{\mathrm{i}}{ }^{2}$ : Shukla's stability variance (Shukla, 1972), $S^{2} d_{i}$ : Deviation from regression (Eberhart and Russell, 1966), $b_{i}:$ regression coefficient (Finlay and Wilkinson,1963), CV $\mathrm{C}_{\mathrm{i}}$ : Environmental coefficient of variance( Francis and Kannenberg, 1978), KR-Rank Sum stability statistic (Kang,1993), $\theta_{(\mathrm{i})}$ : GE variance component (Plaisted, 1960), $\theta_{\mathrm{i}}$ : Mean variance component (Plaisted ve Peterson, 1959), RS: Rank-sum RM-Rank mean.

The genotypes with a low $\mathrm{CV}_{i}$ (environmental variation coefficient), low environmental variance and high mean yield are mostly desired (Francis and Kannenberg, 1978). Although Balc1 and Linas cultivars and G1 and G8 genotypes had low values of CVi parameter, they had yield levels lower than the average. Therefore, Gokturk, Dincer 5-118 and G9 with low CV $i$ values and yield levels greater than the average were considered as stable (Table 4 and Table 5).
Among the parametric stability analysis methods, regression coefficient $\left(b_{i}\right)$ is the most commonly used one. Statistical assessment of regression coefficient is made with the use of t-test based on 1.0. Regression coefficients $\left(b_{i}\right)$ of greater than 1.0 and yield levels of greater than average mean well adaptation to well environments; regression coefficients of lower than 1.0 mean well adaptation to all environments (Finlay and Wilkinson,1963). Accordingly, high-yield genotypes G12, Gokturk, G5 and G6 had regression coefficients $b_{i}>1$ (Table 4). These genotypes are well-adapted to well 
environmental conditions. The genotypes Dincer 5-118, G10, G13, G9 and G2 had greater yields than the average and regression coefficients of less than $1.0\left(b_{i}<1\right)$ (Table 4$)$. These genotypes are well-adapted to all environments. Regression coefficient yields information about adaptation capacity of a genotype rather than stability (Akcura and Turan, 2020).

The genotypes with a greater $\theta_{\mathrm{i}}$ (mean variance) are considered as more stable (Plaisted and Peterson, 1959). According to $\theta_{\text {(i) }}$ (GE variance component) statistics, the genotypes with a greater $(i)$ value are considered as more stable (Plaisted, 1960). The genotypes G5 and Gokturk had yields greater than the average and thus were more stable based on $\theta_{(\mathrm{i})}$ and genotypes G10 and G13 were more stable based on $\theta_{\mathrm{i}}$.

According to non-parametric stability methods of $\mathrm{S},{ }^{(1)} \mathrm{S},{ }^{(2)} \mathrm{S},{ }^{(3)} \mathrm{S},{ }^{(6)} \mathrm{KR}$ and $\mathrm{NP}^{(4)}$, Gokturk was identified as the most stable genotype. G4 was the most stable genotype for $\mathrm{NP}^{(1)}$ and $\mathrm{NP}^{(3)}$ parameters and $\mathrm{G} 9$ for $\mathrm{NP}^{(2)}$ parameter. However, stable G4 genotype had a seed yield of lower than the average. Both parametric and non-parametric methods yielded similar outcomes. However, non-parametric stability measurements had some advantages in interpretation of the results over the parametric stability measurements (Awoke and Sharma, 2016).

If the high values of an investigated trait are desired in experiments conducted with different plants in different environments, the genotypes with low values of parametric and non-parametric parameters are considered as stable (Akcura et al., 2006; Akcura and Kaya, 2008; Zaluski et al., 2020). However, the genotypes with low values of stability parameters should have investigated trait or traits greater than the general average (Akcura et al., 2006). Since the stable genotypes G8, G4 and G1 had low seed yields (Y), these genotypes are not preferred by the breeders and producers. On the other hand, the stable genotypes G5 and G9 with high yields are preferred by breeders and producers and they could be a candidate cultivar. In terms of adaptation capability of these genotypes, it was seen that G5 $\left(b_{i}>1\right)$ was able to adapt well environmental conditions and G9 $\left(b_{i}<1\right)$ was able to adapt all environments. Despite the first rank in yield, G12 with a low stability was considered to have high yields at well climate conditions, in other words, this genotype had a specific adaptation capability, but will have hard times in adaptation to changing conditions $\left(b_{i}>1\right)$. Therefore, G12 could be recommended for special environments.

To better understand the relationships between both parametric and non-parametric stability parameters, principal component analysis of ranking correlations and main component analysis based on ranking correlation matrix were performed. The first and the second principal components of ranking correlations respectively explained 55 and $22 \%$ of total variation (77\% in total) (Figure 1$)$

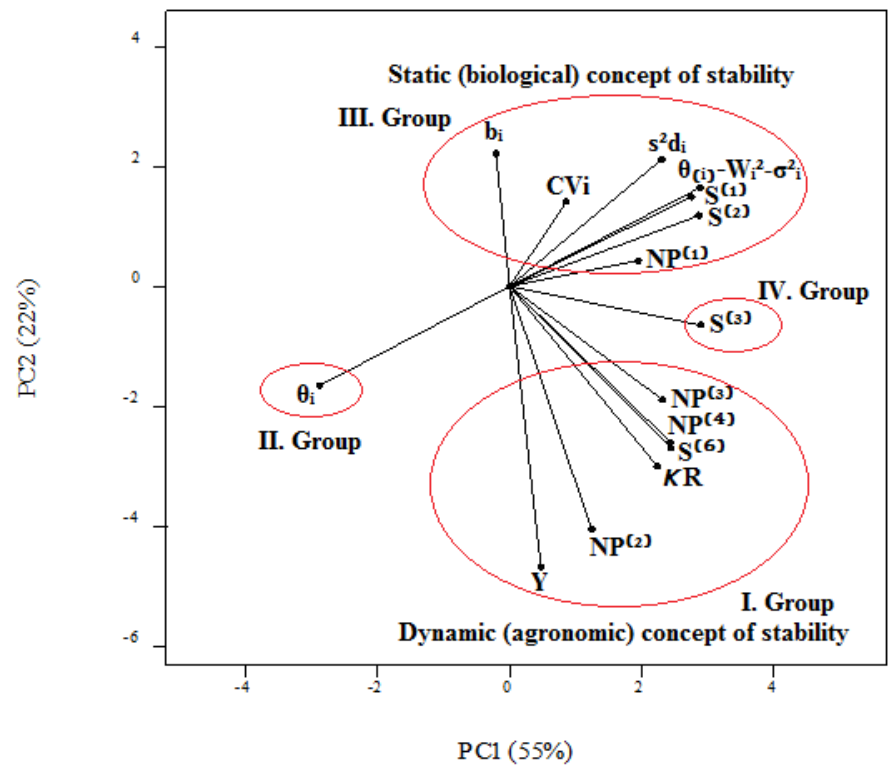

Figure 1. Biplot, which was depicted by PC1 vs. PC2 scores, obtained from principal component analysis conducted based on ranks of 17 safflower genotypes for 16 stability statistics.

Symbols -Y: Seed Yield, $S^{(1)}, S^{(2)}$; $S^{(3)}$ and $S^{(6)}$ : Nassar and Huehn's non-parametric statistics and Huehns statistic, $\mathrm{NP}^{(1-4)}$ Ranks of adjusted seed yield means of genotypes (Thennarasu, 1995), $\mathrm{W}_{\mathrm{i}}^{2}$ : Wricke's ecovalence stability index (Wricke,1962, $\sigma_{\mathrm{i}}^{2}$ : Shukla's stability variance (Shukla, 1972), $\mathrm{S}^{2} \mathrm{~d}_{\mathrm{i}}$ : Deviation from regression (Eberhart and Russell, 1966), $b_{\mathrm{i}}:$ regression coeffient (Finlay and Wilkinson,1963), CV $\mathrm{i}_{\mathrm{i}}$ : Environmental coefficient of variance (Francis and Kannenberg, 1978), KR-Rank Sum stability statistic (Kang,1993), $\theta_{(\mathrm{i})}:$ GE variance component (Plaisted, 1960), $\theta_{\mathrm{i}}$ : Mean variance component (Plaisted ve Peterson, 1959). 
Kang and Magari (1995) and Mohammadi et al. (2012) defined the stability parameters related to high yield performance with concept dynamic stability.

Biplot analysis divided stability methods into four groups based on the relationships among them (Figure 1). These groups are Group I (Y, $\left.\mathrm{S}^{(6)}, \mathrm{NP}^{(2)}, \mathrm{NP}^{(3)}, \mathrm{NP}^{(4)}, K \mathrm{R}\right)$, Group II $\left(\theta_{\mathrm{i}}\right)$, Group III $\left(\mathrm{S},,^{(1)} \mathrm{S},{ }^{(2)} \mathrm{NP},{ }^{(1)} \theta_{(\mathrm{i})}, \mathrm{W}_{\mathrm{i}}{ }^{2}, \sigma^{2}{ }_{\mathrm{i}}, \mathrm{s}^{2} \mathrm{~d}_{\mathrm{i}}\right.$ $, \mathrm{CV} i, \mathrm{~b}_{\mathrm{i}}$ ) and Group IV ( $\left.\mathrm{S}^{(3)}\right)$.
Present findings revealed that in multi-year experiments under different climate conditions, Group I $\left(\mathrm{S}^{(6)}, \mathrm{NP}^{(2)}\right.$, $\left.\mathrm{NP}^{(3)}, \mathrm{NP}^{(4)}, K \mathrm{R}\right)$ stability parameters with significant correlations with the yield could be used in safflower breeding programs conducted to identify high-yield and stable genotypes (Table 6 and Figure 1). These parameters designate dynamic (agronomic) stability concepts. Dynamic stability concept means small G x E interaction and high yield as much as possible. Quantitative traits of the genotypes exhibit similar responds to available or unavailable environmental conditions (Vaezi et al., 2019).

Table 6. Spearman's rank correlation coefficients between yield means (Y) and 16 stability statistics of 17 safflower genotypes tested in 5 years

\begin{tabular}{|c|c|c|c|c|c|c|c|c|c|c|c|c|c|c|c|c|c|}
\hline & $\mathbf{Y}$ & $\mathbf{S}^{(\mathbf{1})}$ & $\mathbf{S}^{(2)}$ & $\mathbf{S}^{(\mathbf{3})}$ & $\mathbf{S}^{(6)}$ & $\mathrm{NP}^{1}$ & $\mathbf{N}^{(2}$ & $\mathbf{N P}^{3}$ & $\mathrm{NP}^{4}$ & $\mathbf{W}_{\mathrm{i}}{ }^{2}$ & $\sigma_{i}^{2}$ & $\mathbf{s}^{2} d_{i}$ & $\mathbf{b}_{\mathrm{i}}$ & $\mathrm{CVi}$ & KR & $\boldsymbol{\theta}_{(\mathrm{i})}$ & $\theta_{\mathrm{i}}$ \\
\hline $\mathbf{Y}$ & 1.00 & & & & & & & & & & & & & & & & \\
\hline $\mathbf{S}^{(\mathbf{1})}$ & -0.15 & 1.00 & & & & & & & & & & & & & & & \\
\hline $\mathbf{S}^{(2)}$ & -0.08 & $0.98 * *$ & 1.00 & & & & & & & & & & & & & & \\
\hline $\mathbf{S}^{(\mathbf{3})}$ & 0.25 & $0.85^{* *}$ & $0.88 * *$ & 1.00 & & & & & & & & & & & & & \\
\hline $\mathbf{S}^{(\boldsymbol{6})}$ & $0.64 * *$ & $0.56^{* * *}$ & $0.61 * *$ & $0.85^{* *}$ & 1.00 & & & & & & & & & & & & \\
\hline $\mathbf{N P}(\mathbf{1})$ & -0.04 & $0.52 *$ & $0.53^{*}$ & $0.52 *$ & 0.40 & 1.00 & & & & & & & & & & & \\
\hline $\mathbf{N P}^{(2)}$ & $0.80 * *$ & 0.03 & 0.09 & 0.45 & $0.76 * *$ & 0.06 & 1.00 & & & & & & & & & & \\
\hline $\mathbf{N P} \mathbf{P}^{(\mathbf{3})}$ & $0.45 *$ & $0.44 *$ & $0.50 *$ & $0.63 * *$ & $0.70 * *$ & $0.64 * *$ & $0.60 * *$ & 1.00 & & & & & & & & & \\
\hline $\mathbf{N P}^{(4}$ & $0.61 * *$ & $0.59 * *$ & $0.62 * *$ & $0.87 * *$ & $0.98 * *$ & 0.34 & $0.76^{* * *}$ & $0.67 * *$ & 1.00 & & & & & & & & \\
\hline $\mathbf{W}_{\mathrm{i}}^{2}$ & -0.18 & $0.87 * *$ & $0.88 * *$ & $0.75^{* *}$ & $0.50 *$ & $0.58 * *$ & 0.10 & $0.56 * *$ & $0.50^{*}$ & 1.00 & & & & & & & \\
\hline$\sigma_{i}^{2}$ & -0.18 & $0.87 * *$ & $0.88 * *$ & $0.75^{* *}$ & $0.50 *$ & $0.58 * *$ & 0.10 & $0.56 * *$ & $0.50 *$ & 1.00 & 1.00 & & & & & & \\
\hline $\mathbf{s}^{2} d_{i}$ & -0.23 & $0.69 * *$ & $0.71 * *$ & $0.53 *$ & 0.27 & 0.26 & 0.01 & 0.37 & 0.27 & $0.86^{* * *}$ & $0.86 * *$ & 1.00 & & & & & \\
\hline $\mathbf{b}_{\mathrm{i}}$ & -0.37 & 0.04 & 0.04 & -0.01 & -0.14 & 0.03 & -0.26 & -0.19 & -0.13 & -0.03 & -0.03 & 0.02 & .001 & & & & \\
\hline $\mathrm{CVi}$ & -0.15 & 0.26 & 0.28 & 0.32 & 0.21 & 0.04 & 0.06 & 0.04 & 0.22 & 0.25 & 0.25 & 0.31 & $0.85^{* *}$ & 1.00 & & & \\
\hline KR & $0.71 * *$ & 0.39 & $0.49 *$ & $0.69 * *$ & $0.83 * *$ & 0.39 & $0.75^{* *} *$ & $0.75 * *$ & $0.81 * *$ & $0.46^{*}$ & $0.46^{*}$ & 0.32 & -0.33 & 0.001 & 1.00 & & \\
\hline $\boldsymbol{\theta}_{(\mathbf{i})}$ & -0.18 & $0.87 * *$ & $0.88 * *$ & $0.75^{* *}$ & $0.50 *$ & $0.58 * *$ & 0.10 & $0.56 * *$ & $0.50 *$ & $1.00 * *$ & $1.00 * *$ & $0.86^{* *}$ & -0.03 & 0.25 & $0.46^{*}$ & 1.00 & \\
\hline & & - & - & - & & - & & - & & - & - & - & & & & & \\
\hline$\theta_{\mathrm{i}}$ & 0.18 & $0.87 * *$ & $0.88 * *$ & $0.75^{* *}$ & $-0.50 *$ & $0.58 * *$ & -0.10 & $0.56 * *$ & $-0.50 *$ & $1.00 * *$ & $1.00 * *$ & $0.86^{* *} *$ & 0.03 & -0.25 & $-0.46^{*}$ & $-1.00 * *$ & 1.0 \\
\hline
\end{tabular}

Group II $\left(\theta_{\mathrm{i}}\right)$ and Group IV ( $\left.\mathrm{S}^{(3)}\right)$ have positive, but weak correlations with yield (Table 6 and Figure 1). Therefore, these stability statistics could be used to select the genotypes with moderate yield levels and high stability (Akcura et al., 2009).

Group III (S, $,^{(1)} \mathrm{S},{ }^{(2)} \mathrm{NP},{ }^{(1)} \theta_{(\mathrm{i})}, \mathrm{W}_{\mathrm{i}}{ }^{2}, \sigma^{2}, \mathrm{~s}^{2} \mathrm{~d}_{\mathrm{i}} \mathrm{CVi}, \mathrm{b}_{\mathrm{i}}$ ) parameters have a negative correlation with yield and generally designated low-yield stable genotypes (Table 6 and Figure 1). These parameters are so called as biological (static) parameters (Akcura et al., 2009). In biological (static) stability, a genotype has a stable performance regardless of the environmental variations, therefore, the variance among the environments is assumed to be zero. These genotypes could not present sufficient responds to improvements in growing conditions. In other words, designates low-yield and stable genotypes. Therefore, biological / static stability concept is not preferred by majority of breeders preferring high-yield genotypes with a potential respond to better environmental conditions. Highyield performance is the primary target of the breeders; thus, they mostly prefer a dynamic stability concept (Becker and Leon, 1988).

Besides parametric and non-parametric statistics, biplot graphs improved the success in identifying the stability parameters suitable for selections in safflower breeding programs. Similarly, Vaezi et al. (2019) in barley,
Goksoy et al. (2019) in soybean, Oyekunle et al. (2016) in maize and Jamshidmoghaddam and Pourdad (2013) in safflower, indicated significant advantages of combined use of parametric and non-parametric stability statistics with GGE biplot approaches in identification of stable genotypes.

\section{CONCLUSION}

Gokturk, Dincer 5-118, G5 and G9 genotypes were identified as stable based on majority of stability methods and these genotypes had seed yields greater than the general averages. On the ond, stable genotypes G8, G4 and G1 had seed yields lower than the general averages.

Present findings revealed that in multi-year yield experiments Group I $\left(\mathrm{S}^{(6)}, \mathrm{NP}^{(2)}, \mathrm{NP}^{(3)}, \mathrm{NP}^{(4)}, K \mathrm{R}\right)$ could be used as selection criteria to determine high-yield and stable genotypes in safflower breeding programs. The other groups of stability parameters theoretically designate stable genotypes, but they are much preferred by the breeders since they were not related to high yield in practice. Genotype rankings for the same group parameters are close to each other, even the same for some parameters $\left(\theta_{(\mathrm{i})}, \mathrm{W}_{\mathrm{i}}{ }^{2}\right.$, $\left.\sigma^{2}{ }_{i}\right)$.

Selection of superior genotypes is an essential part of safflower breeding programs under varying and unforeseen climate and rain-fed conditions. Therefore, multi-year 
experiments facilitate the selection of ideal genotypes with both high seed yield and high stability. As compared to the other genotypes, selected genotypes (G5 and G9) have reasonable seed yield performance and stability. The graphical methods generated through the use of both parametric and non-parametric statistics improved the success in identification of suitable stability parameters in safflower breeding. Instead of using several methods to identify stable genotypes, a single parameter from each group of methods will be sufficient. The stable and highyield genotype G9 was registered in 2019 in Turkey under the name of "Koc".

\section{LITERATURE CITED}

Akcura, M. and Y. Kaya. 2008. Non-parametric stability methods for interpreting genotype by environment interaction of bread wheat genotypes (Triticum aestivum L.). Genetics and Molecular Biology 31(4): 906-913.

Akcura, M., Y. Kaya, S. Taner. 2009. Evaluation of durum wheat genotypes using parametric and nonparametric stability statistics. Turkish Journal of Field Crops 14(2): 111-122.

Akcura, M., Y. Kaya, S. Taner, R. Ayranc1. 2006. Parametric stability analyses for grain yield of durum wheat. Plant Soil and Environment 52(6):254

Akcura, M. and A. Turan. 2020. Investigation of Genotype $\times$ Environment Interaction with different methods in grain yield of edible cluster bean. Turkish Journal of Agricultural and Natural Sciences 7 (3): 798-805.

Awoke, S. and M.K. Sharma. 2016. Parametric and nonparametric methods to describe genotype by environment interaction and grain yield stability of bread wheat. Statistics and applications. 14: 9-29.

Becker, H.C. and J. Leon. 1988. Stability analysis in plant breeding. Plant Breed. 101:1-23.

Eberhart, S.A.T. and W.A. Russell.1966. Stability parameters for comparing varieties. Crop Sci 6:36-40.

Finlay, K.W. and G.N. Wilkinson. 1963. Adaptation in a plant breeding programme. Aust J Agric Res. 14:742-754.

Flores, F., M.T. Moreno and J.I. Cubero. 1998. A comparison of univariate and multivariate methods to analyze $\mathrm{G} \times \mathrm{E}$ interaction. Field Crops Research 56: 271-286.

Fox, P.N., B. Skovmand, B.K. Thompson, H.J. Braun and R. Cormier 1990. Yield and adaptation of hexaploid spring triticale. Euphytica 47: 57-64.

Francis, TR. and LW. Kannenberg .1978. Yield stability studies in short-season maize: I. A descriptive method for grouping genotypes. Canadian Journal of Plant Science 58: 1029-1034

Goksoy, A.T., M. Sincik, M. Erdogmus, M. Ergin, S. Aytac, G, Gumuscu 2019. The Parametric and non-parametric stability analyses for interpreting genotype by environment interaction of some soybean genotypes. Turkish Journal of Field Crops 24(1): 28-38.

Hocaoglu, O., K. Akan and M. Akcura. 2020. Evaluating leaf rust reactions of pure bread wheat landrace lines using nonparametric statistics. Phytoparasitica 48: 261-271.

Huehn, M. 1990. Non-parametric measures of phenotypic stability. Part 1: Theory. Euphytica 47: 189-199.

Jamshidmoghaddam, M. and S.S. Pourdad. 2013. Genotype $\times$ environment interactions for seed yield in rainfed winter safflower (Carthamus tinctorius L.) multi-environment trials in Iran. Euphytica 180:321-335.

Kang, M.S. 1993. Simultaneous selection for yield and stability in crop performance trials: Consequences for growers. Agron. J. 85: 754-757.
Kang, M.S. and R. Magari.1995. STABLE: A BASIC program for calculating stability and yield-stability statistics. Agron. J. 87: 276-277.

Ketata, H. 1988. Genotype $\mathrm{x}$ environment interaction. (Proceeding of the workshop on biometrical techniques for cereal breeders). ICARDA, Aleppo, Syria. pp. 16-32.

Koc, H. 2020. Effects of seedling stage drought on seed yield, oil rate and oil yield in safflower (Carthamus tinctorius L) genotypes. KSU Journal of Agriculture and Nature 23(6): 1626-1633.

Mohammadi, M., R. Karimizadeh, N. Sabaghnia and M.K. Shefazadeh. 2012. Genotype $\times$ environment interaction and yield stability analysis of new improved bread wheat genotypes. Turk J Field Crops. 17 (1): 67-73.

Nassar, R. and M. Huehn. 1987. Studies on estimation of phenotypic stability: Tests of significance for nonparametric measures of phenotypic stability. Biometrics 43: 45-53.

Oyekunle, M., A. Haruna, B.B. Apraku, I.S. Usman, H. Mani, S.G. Ado, G. Olaoye, K. Obeng-Antwi, R.O. Abdulmalik and H.O Ahmad. 2016. Assessment of early-maturing maize hybrids and testing sites using GGE biplot analysis. Crop Sci. 57:1-9.

Plaisted, R.I. and L.C. Peterson. 1959. A technique for evaluating the ability of selection to yield consistently in different locations or seasons. American Potato Journal 36: 381-385.

Plaisted, RL. 1960. A shorter method for evaluating the ability of selections to yield consistently over locations. American Potato Journal 37: 166-172.

Pour-Aboughadareh, A., M. Yousefian, H. Moradkhani, P. Poczai and K.H.M. Siddique. 2019. STABILITYSOFT: a new online program to calculate parametric and non- parametric stability statistics for crop traits. Appl. Plant Sc.i 7: e1211.

Semenov, M.A. and N.G. Halfor. 2009. Identifying target traits and molecular mechanisms for wheat breeding under a changing climate. Journal of Experimental Botany 60 (10): 2791-2804.

Shukla, G.K. 1972. Some statistical aspects of partitioning genotype-environmental components of variability. Heredity 29: 237-245.

Simmonds, N.W. 1991. Selection for local adaptataion in a plant breeding programme. Theor. Applied Genet. 82 (3): 363-367.

Sozen, O, U. Karadavut, H. Ozcelik, H. Bozoglu and M. Akcura. 2018. Genotype $\times$ Environment interaction of some dry bean (Phaseolus vulgaris L.) genotypes. Legume Research (41) 2: 189-195.

Thennarasu, K. 1995. On certain non-parametric procedures for studying genotype-environment interactions and yield stability. Indian J. Genet. 60: 433-439.

Vaezi, B., A. Pour-Aboughadareh, R. Mohammadi, A. Mehraban, T. Hossein-Pour.2019. Integrating different stability models to investigate genotype $\times$ environment interactions and identify stable and high-yielding barley genotypes. Euphytica 215(4):63.

Wricke, G. 1962. Ubereine Methode zur Erfassung der okologischen Streubreite in Feldversuchen. Zeitschrift fur Pflanzenzuchtung 47: 92-96.

Yan, W. 2014. Crop Variety Trials: Data Management and Analysis John Wiley and Sons, 349.

Yildırım, M.B., C.F. Caliskan and Y. Arshad. 1992. Determining the environmental adaptability of some potato genotypes using different stability parameters. Turkish Journal of Agriculture and Forestry 3(16): 621-629.

Zaluski, D., J. Tworkowski, M. Krzyżaniak, M.J. Stolarski and J. Kwiatkowski. 2020. The characterization of 10 Spring camelina genotypes grown in environmental Conditions in North-Eastern Poland. Agronomy 10 (1): 1-13. 